\title{
Corrosion Problem and Prevention Technology in Wire Electrical Discharge Machining
}

\author{
Yozo Sakai*, Akihiro Goto**, Kazushi Nakamura**, Seiji Sato***
}

(Received on December 1, 2005)

* Industrial Automation Machinery Marketing Division, Mitsubishi Electric Corporation, Tokyo ,100-8310

** EDM Systems Department, Nagoya Works, Mitsubishi Electric Corporation, Nagoya ,.461-8670

*** Industrial Mechatronics Solution Center, Mitsubishi Electric Corporation, Saitama ,336-0027

\begin{abstract}
Wire Electrical Discharge Machine (WEDM) is used widely for the manufacturing of the high precision stamping dies. However the recast layer and deteriorated layer formed on the surface of the machined workpiece affect the life of the tool \& dies, especially for those made of cemented carbide.

Inspection of these surfaces showed that the deteriorated layer of the cemented carbide in submerged machining was caused by the elution of Co element. The micro cracks on the wire EDM machined (WEDMed) surface are considered the main reason for the corrosion (elution). Either in WEDM finishing or grinding process, elution still occurs when the workpiece is left under water for long period of time.
\end{abstract}

\section{INTRODUCTION}

In wire electrical discharge machining (WEDMing) tool steels and some other metals, the recast layer due to heat energy, rust in case of water-soluble machining fluid, and the deteriorated layer (corrosion layer) owing to electrical conditions are formed on the surface of the workpiece. There is a paper $^{(1)}$ which discussed the fundamental study of this issue. This paper discusses the inspection method with micro-observation, the generation mechanism and how to prevent corrosion layer in submerged WEDMing.

\section{MECHANISM OF CORROSION IN SUBMERGED WIRE ELECTRICAL DISCHARGE MACHINING}

When water-soluble fluids are used in machining, there is the possibility that the components of the workpiece are eluted into the working fluid. The main reasons for this elution phenomenon are stated follows.

\subsection{Problem of Machining Voltage}

Whenever a workpiece is machined using direct current source, ionization occurs. Since the normal setup has the workpiece in positive polarity, the metal components are ionized and dissolved into the machining fluid which leads to corrosion (electrolytic corrosion).

$$
\begin{aligned}
& \text { For } \begin{array}{r}
\text { Cemented Carbide }(\mathrm{WC}-\mathrm{Co}): \\
\\
\mathrm{Co} \rightarrow \mathrm{Co}^{2+}+2 \cdot \mathrm{e}^{-}
\end{array} \\
& \text {For Steel }(\mathrm{Fe}): \mathrm{Fe} \rightarrow \mathrm{Fe}^{2+}+2 \cdot \mathrm{e}^{-}
\end{aligned}
$$

In the past, the main cause of the corrosion problem was the electrolytic corrosion. However, after the commercializing of the anti-electrolysis power supply, which is designed to set the average gap voltage to $0 \mathrm{~V}$, the problem of the electrolytic corrosion due to the machining voltage has disappeared.

\subsection{Adhesion of Sludge}

When different kinds of metals come into contact, corrosion occurs (galvanic corrosion). In case of wire electrical discharge machining, corrosion of steel-workpiece accelerates when copper comes in contact with the steel. Moreover, the machining sludge adhered the workpiece accelerates the corrosion too.

\subsection{Problem of Rust and Elution}

Fig.1 shows the principle of metal component elution. When workpiece is left under water, corrosion advances with the elution of Co for cemented carbide and $\mathrm{Fe}$ for steel (->rust). In case of steel, the following kind of reaction occurs under water. Similarly, Co replaces $\mathrm{Fe}$ in the case of cemented carbide. 
$\mathrm{Fe}$ of the workpiece dissolves into $\mathrm{Fe}^{2+}$ and electrons $\left(\mathrm{Fe} \rightarrow \mathrm{Fe}^{2+}+2 \cdot \mathrm{e}\right)$, where the next reaction advances by using these electrons: $1 / 2 \cdot \mathrm{O}_{2}+\mathrm{H}_{2} \mathrm{O}$ $+2 \mathrm{e}->2 \mathrm{OH}^{-}$

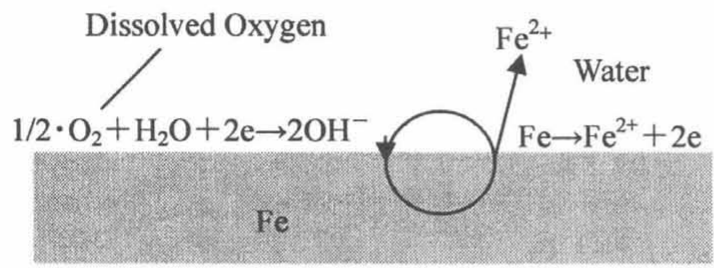

Fig.1 Principle of metal component elution

\section{INSPECTION OF MACHINED SURFACE}

\subsection{Inspection Method}

In order to inspect corrosion and examine the vicinity of machined surface in detail, the below-mentioned processes were carried out (Fig. 2):

1. Open surface machining with wire electrical discharge machining.

2. Grinding and finishing of WEDMed surface with an angle of $5^{\circ}$. (The deteriorated layer depth appears to be enlarged by the grinding process. When observed perpendicularly from the EDM surface, it enlarges to $1 / \tan 5^{\circ}$ (approximately 11 times).)

3. Examining the boundary layer between the ground and WEDMed surfaces.

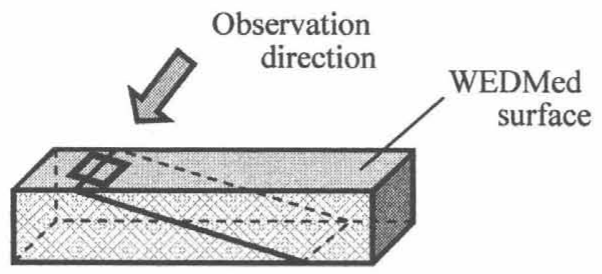

Fig.2 Inspection method of machine affected layer

Experiments were conducted with cemented carbide (Kyoritsu Gokin Co.,Ltd: KD20), where hardness and die life span deteriorates when elution of binder Co occurs. As indicated also in Section 2.1, Mitsubishi Electric Corporation's PX05 model with anti- electrolysis power supply was used as the experiment machine. The specific resistance of the machining fluid was $1 \times 10^{5} \Omega \mathrm{cm}$.

\subsection{Inspection Results}

Fig. 3 and 4 show the machined surface characteristics finished to $2.5 \mu \mathrm{mRz}$ and $0.5 \mu \mathrm{mRz}$, respectively. Depending on the occurrence of micro cracks, a corrosion layer in thickness of $8 \mu \mathrm{m}$ is observed for the surface with roughness of $2.5 \mu \mathrm{mRz}$. On the other hand, there is almost no corrosion for the surface which is finished to $0.5 \mu \mathrm{mRz}$.

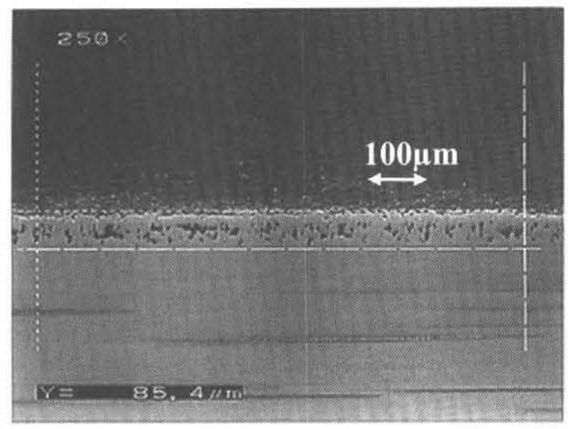

Fig.3 WEDMed surface with $2.5 \mu \mathrm{mR} \mathrm{z}$

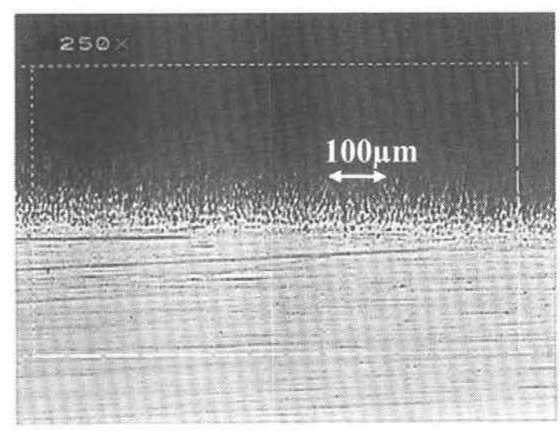

Fig.4 WEDMed surface with $0.5 \mu \mathrm{mR} \mathrm{z}$

Fig. 5 shows the WEDMed surface of a workpiece that is left 8 hours inside the working fluid (for same machining conditions as in Fig. 4). A deteriorated layer in thickness of about $8 \mu \mathrm{m}$ can be observed. A magnified SEM photograph of this part is shown in Fig. 6. According to this photograph, it can be understood that the deteriorated layer is not the result of melting and re-solidification due to heat, but it is the result of the eluted and missing binder Co element. This result shows that a corrosion layer is formed when the workpiece is left under water.

If the deteriorated layer is caused by corrosion, it is expected that corrosion will also occur on surface without WEDMing. Fig. 7 presents the SEM photograph of an identical ground workpiece surface. The similar result with Figure 6 verifies that a corrosion layer is formed under water. 


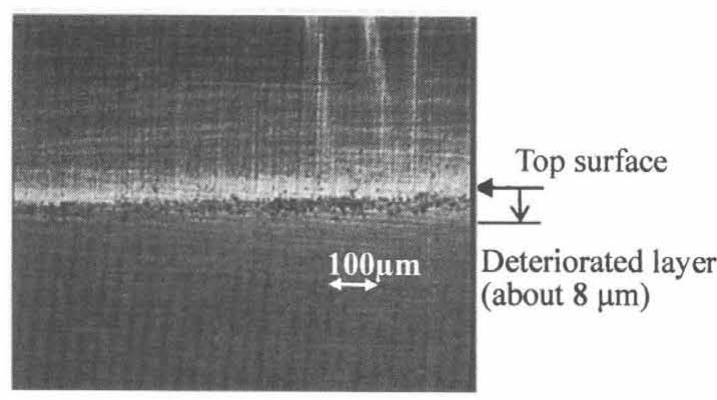

Fig. 5 WEDMed surface after 8 hours

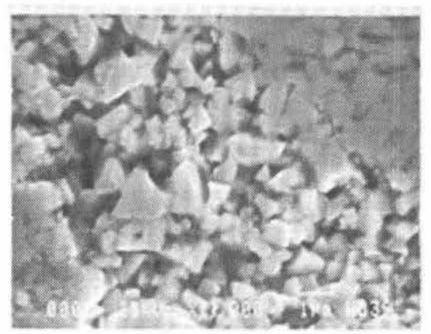

Fig. 6 Magnified view (WEDM)

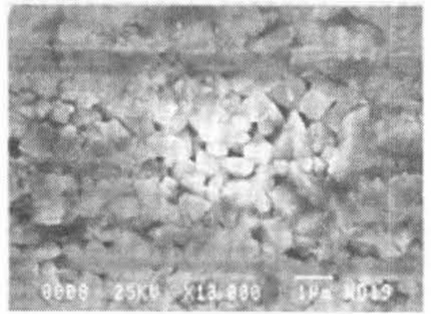

Fig. 7 Magnified view (Grinding)

\section{CORROSION PREVENTION TECHNOLOGY}

\subsection{Anti-corrosion Circuit}

In order to prevent the corrosion reaction, an electron flow without component elution of workpiece is necessary. For this purpose, an electrical corrosion prevention circuit is illustrated in Fig. 8.

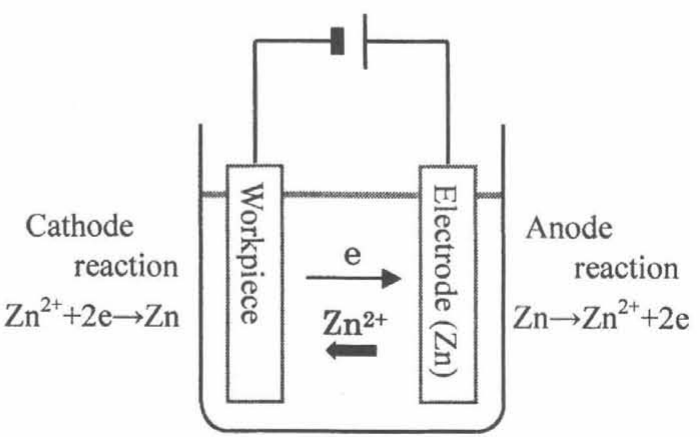

Fig.8. Electrical anti-corrosion circuit
A zinc plate is installed onto the nozzle of the wire electrical discharge machine where voltage is applied between the zinc plate and the workpiece. The zinc of the electrode forms a tiny film on the workpiece surface, since zinc is a metal whose ionization characteristic is higher than $\mathrm{Fe}$ and $\mathrm{Co}$. Zinc also has an effect to prevent galvanic corrosion when different metals come into contact with each other.

\subsection{Effect of Prevention}

Two different surfaces of roughness $0.5 \mu \mathrm{mRz}$ and $2.5 \mu \mathrm{mRz}$ are machined with the electrical anti-corrosion circuit. Fig. 9 shows the surfaces after the workpiece was left 24 hours under water. Fig. 10 presents the surfaces for standard circuit. It is observed that corrosion starts forming in Fig. 10.

Surface characteristics after 96 hours are shown in Fig. 11 and 12. It is observed that corrosion occurs even when the original electrical anti-corrosion circuit is used. The entire evaluation results are arranged in Table 1.

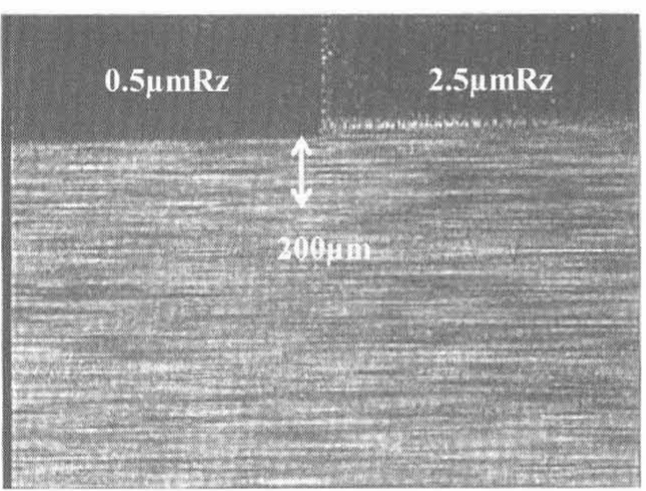

Fig. 9 With anti-corrosion circuit (after 24hrs)

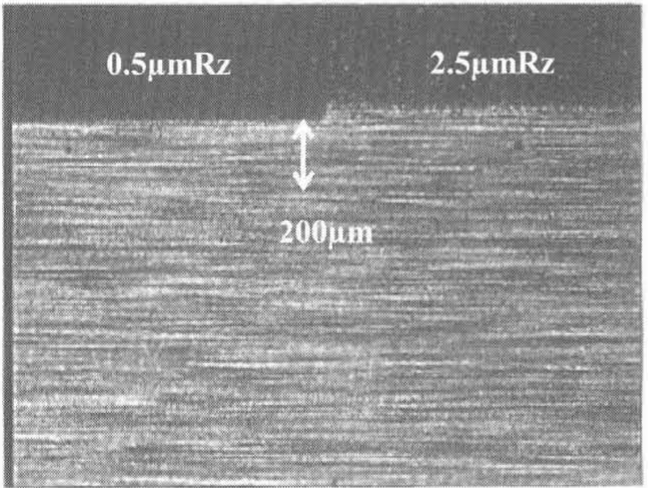

Fig. 10 Without anti-corrosion circuit (after 24hrs) 


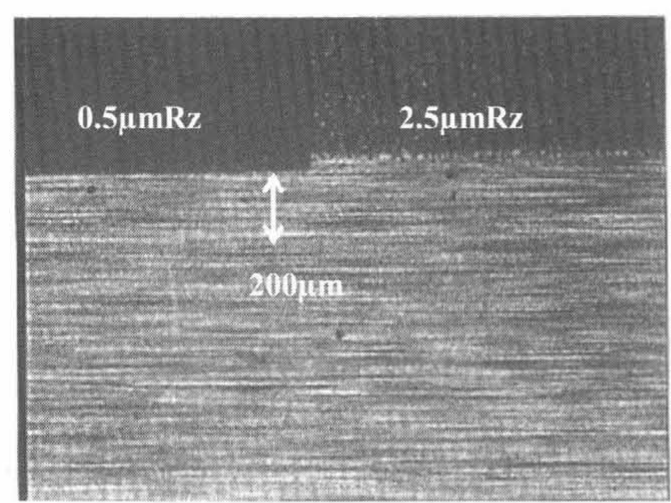

Fig.11 With anti-corrosion circuit (after 96hrs)

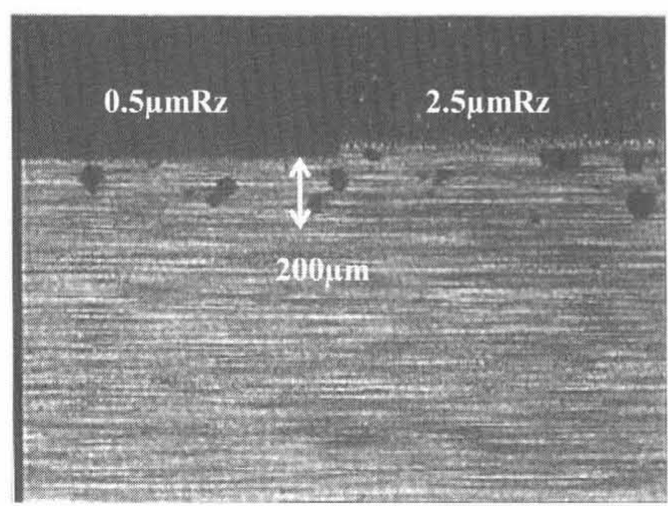

Fig.12 Without anti-corrosion circuit (after 96hrs)

Table 1. Comparison of corrosion protection results depending on immersion time

\begin{tabular}{|l|l|l|}
\hline $\begin{array}{l}\text { Immersion } \\
\text { time } \\
\text { (hours) }\end{array}$ & $\begin{array}{l}\text { With } \\
\text { anti-corrosion } \\
\text { circuit }\end{array}$ & $\begin{array}{l}\text { Without } \\
\text { anti-corrosion } \\
\text { circuit }\end{array}$ \\
\hline 12 & No corrosion & corrosion \\
\hline 24 & No corrosion & corrosion \\
\hline 48 & $\begin{array}{l}\text { minute } \\
\text { corrosion }\end{array}$ & corrosion \\
\hline 96 & corrosion & corrosion \\
\hline
\end{tabular}

\section{CONCLUSION}

WEDMed surfaces were slantwise ground and finished in order to magnify and examine surface vicinity. Inspection of these surfaces showed that the deteriorated layer of the cemented carbide in submerged machining was caused by the elution of
Co element. Corrosion (elution) does not occur on the surface, but does occur in small amounts below the surface where cracks exist. Elution of Co becomes less in finished surfaces since these surfaces are almost free of cracks. However, either in finishing EDM or in grinding process, elution still occurs when the workpiece is left under water for a long period of time.

Certain results were obtained with the use of electrical anti-corrosion circuit, which utilizes zinc electrode. In the next articles, measures for corrosion prevention other than the electrical circuit will be discussed.

\section{REFERENCE}

1) H.Obara, H.Satou, M.Hatano, "Fundamental study on corrosion of cemented carbide during wire EDM", J.Material Processing Technology, 149,p.370(2004) 